\title{
Pirfenidone suppresses bleomycin-induced pulmonary fibrosis and periostin expression in rats
}

\author{
XIAOXIA SONG ${ }^{1}$, WENCHENG YU ${ }^{2}$ and FANG GUO ${ }^{3}$ \\ Departments of ${ }^{1}$ Intensive Care Unit and ${ }^{2}$ Respiratory Medicine, The Affiliated Hospital of Qingdao University, Qingdao, \\ Shandong 266003; ${ }^{3}$ Department of Pediatrics, Laiwu City People's Hospital, Laiwu, Shandong 271100, P.R. China
}

Received May 5, 2016; Accepted October 20, 2017

DOI: $10.3892 /$ etm.2018.6378

\begin{abstract}
The aim of the present study was to investigate the effect of pirfenidone on bleomycin-induced lung fibrosis in rats, in order to elucidate the underlying mechanism of periostin-induced fibrosis. The lung fibrosis model was constructed using a single intratracheal instillation of bleomycin in rats. The normal rats without bleomycin administration were used as controls $(n=24)$. Bleomycin-treated rats were randomized into the model $(\mathrm{M})$ or pirfenidone $(\mathrm{P})$ group ( $n=24$ per group). Rats were sacrificed on days 7,14 and 28 following treatment. Hematoxylin-eosin and Masson's trichrome staining were performed to analyze pulmonary alveolitis and fibrosis. Periostin location was detected by immunohistochemistry. Hydroxyproline content, and expression of periostin and transforming grow th factor (TGF)- $\beta 1$ were detected by ELISA, reverse transcription-quantitative polymerase chain reaction or western blotting. Correlation of periostin expression with hydroxyproline and TGF- $\beta 1$ content was also analyzed. Histological findings demonstrated that pirfenidone significantly inhibited bleomycin-induced lung fibrosis and reduced the hydroxyproline content on day 14 and day 28 compared with the model group $(\mathrm{P}<0.05$ or $\mathrm{P}<0.01)$. Furthermore, the bleomycin-induced increased protein expression of periostin and TGF- $\beta 1$ was also significantly suppressed by pirfenidone on days $14(\mathrm{P}<0.01)$ and 28 (data not shown). Furthermore, periostin expression was significantly correlated with hydroxyproline and TGF- $\beta 1$ content, and fibrosis score $(\mathrm{P}<0.001)$. The present findings suggest that the antifibrotic effect of pirfenidone may be achieved by suppression of periostin and TGF- $\beta 1$ expression in rat pulmonary fibrogenesis.
\end{abstract}

Correspondence to: Dr Wencheng Yu, Department of Respiratory Medicine, The Affiliated Hospital of Qingdao University, 16 Jiangsu Road, Qingdao, Shandong 266003, P.R. China

E-mail: qdyuwencheng@163.com

Key words: bleomycin, idiopathic pulmonary fibrosis, periostin, pirfenidone, transforming growth factor- $\beta 1$

\section{Introduction}

Idiopathic pulmonary fibrosis (IPF) is characterized by progressive scarring of the lung parenchyma and is a chronic, devastating disorder, the underlying cause of which remains to be elucidated (1). Patient prognosis is very poor and there are currently no pharmacologic therapies to improve the survival rate (2). In recent years, considerable progress has been made in understanding the pathogenesis of pulmonary fibrosis, however, the precise molecular mechanism of IPF remains poorly understood.

Periostin, which is a matricellular protein belonging to the fasciclin family, influences cell function by regulating cell-matrix interactions rather than serving direct structural roles $(3,4)$. Periostin is able to activate nuclear factor- $\mathrm{\kappa} \mathrm{B} /$ signal transducer and activator of transcription factor 3 , phosphoinositide 3-kinase/protein kinase B and focal adhesion kinase signaling through binding $\alpha \mathrm{v}$ integrins (5), and also regulates the expression of factors including transforming growth factor (TGF)- $\beta 1, \alpha$-smooth muscle actin ( $\alpha$-SMA), and a number of chemokines (6). Periostin is upregulated in various types of cancer and associated with a number of tumor cell processes including invasion, angiogenesis, and metastasis as described previously (7). Furthermore, periostin is believed to have a role in wound repair, cardiac hypertrophy and ventricular remodeling by regulating the production and deposition of extracellular matrix $(8,9)$. In recent years, periostin has been shown to serve an important role in the process of fibrosis, which has suggested its potential role as a biomarker and therapeutic target for IPF (6,10-13).

Although effects to disrupt IPF progression, such as suppressing the activity of key cytokines and growth factors, have previously been implemented in animal models (14), there are no available therapies to stop and reverse its progression, at present. Pirfenidone [5-methyl-1-2-(1H)-pyridone] is a newly developed anti-fibrotic agent that has been approved for the treatment of IPF in 2011 (1). Pirfenidone is able to inhibit profibrotic and proinflammatory cytokine secretion and subsequently limits the decline of pulmonary function in patients with IPF (15-17). However, the underlying mechanisms for the beneficial effects of pirfenidone on lung fibrosis are not fully understood. The aim of the present study was to investigate the impact of pirfenidone on the expression of periostin and TGF- $\beta 1$ in bleomycin-induced lung fibrosis in rats. 


\section{Materials and methods}

Animals and treatments. The present study was performed in accordance with the guidelines of the National Institutes of Health (NIH) Guide for the Care and Use of Laboratory Animals, and was approved by the Animal Care and Use Committee of the Medical College of Qingdao University (Qingdao, China). A total of 72 male Wistar rats (specific pathogen-free; age, 6-8 weeks old; weight, 200土25 g) were purchased from Qingdao DaRen Fortune Animal Technology Co., Ltd. (Qingdao, Shandong, China). Animals were housed on a temperature $\left(\sim 22^{\circ} \mathrm{C}\right)$ and humidity ( $\left.25 \%\right)$ controlled environment with $12 \mathrm{~h} / 12 \mathrm{~h}$ light cycle and free access to food and water at the Laboratory Animal Center, Medical College of Qingdao University.

A single intratracheal instillation of $5 \mathrm{mg} / \mathrm{kg}$ bleomycin (Nippon Kayaku Co., Ltd., Tokyo, Japan) dissolved in normal saline was administered to induce pulmonary fibrosis in rats on day 0 (18). The control (C) group $(n=24)$ was intratracheally administered with an equal volume of normal saline $(10 \mathrm{ml} / \mathrm{kg}$ body weight). Bleomycin-treated rats were randomly divided into the two groups ( $n=24$ per group): The model $(\mathrm{M})$ and pirfenidone $(\mathrm{P})$ groups. From the second day following modeling, pirfenidone (50 mg/kg; Beijing Kangdini Pharaceutical Co., Ltd., Beijing, China) was orally administered once daily to rats in $\mathrm{P}$ group via a gastric tube. Prior to the present study, preliminary experiments were performed with different concentrations of pirfenidone (10, 30, 50 and $100 \mathrm{mg} / \mathrm{kg}$ ) and $50 \mathrm{mg} / \mathrm{kg}$ induced the most notable inhibitory effects on bleomycin-induced pulmonary fibrosis in rats according to the histological analysis (data not shown). For rats in $\mathrm{M}$ group, $2 \mathrm{ml}$ saline was orally administered once daily. Subsequently, at 7,14 and 28 days following the beginning of the experiment, 8 rats were sacrificed at each time point and lungs were isolated and perfused with saline prior to histology analysis.

Histological analysis. The left lungs of rats from each group were collected for morphologic studies. Lungs were inflated with $4 \%$ paraformaldehyde and fixed in formalin at $4{ }^{\circ} \mathrm{C}$ for $24 \mathrm{~h}$. After embedding by paraffin, lungs were cut into $5-\mu \mathrm{m}$ slices and stained with hematoxylin and eosin (H\&E) and Masson's trichrome kits (cat. no. MST-8003; Fuzhou Maixin Biotechnology Development Co., Ltd., Fuzhou, China) according to manufacturer's protocol. To assess alveolitis and fibrosis, H\&E Masson-stained sections were evaluated via semi-quantitative histology by a pathologist who was blinded to the treatment groups, using a light microscope at x200 and a scoring system, as described previously $(19,20)$.

Hydroxyproline assay. The content of hydroxyproline in lung tissues was determined using a commercial ELISA kit (cat. no. CEA621Ge; Uscn Life Science, Inc., Wuhan, China) according to the manufacturer's protocol. Briefly, lung issue samples were homogenized using a pestle and mortar in the liquid nitrogen and lysed using RIPA lysis buffer (cat. no. 20-188; Merck Millipore, Billerica, MA, USA) contained with phosphatase inhibitor cocktail (cat. no. 524627; Life Technologies; Thermo Fisher Scientific, Inc., Waltham, MA, USA) at $4^{\circ} \mathrm{C}$ for $30 \mathrm{~min}$. Following this, the lysates were centrifuged at $10,000 \mathrm{x} \mathrm{g}, 4^{\circ} \mathrm{C}$ for $10 \mathrm{~min}$, and supernatants were harvested and quantified using the BCA Protein assay kit (cat. no. 71285; Life Technologies; Thermo Fisher Scientific, Inc.). Then, lung tissue extractions were added to the 96-well ELISA plate, which was coated with rat horseradish peroxidase (HRP)-conjugated hydroxyproline antibody, provided by the ELISA kit. The hydroxyproline concentration was quantified following addition of the chromogenic substrate tetramethylbenzidine and analyzed using a microtiter plate reader (BioTek Instruments, Inc., Winooski, VT, USA) at a wavelength of $450 \mathrm{~nm}$.

Immunohistochemistry. Immunohistochemical staining was performed to view the distribution of periostin. Primarily, lung sections were incubated with $3 \% \mathrm{H}_{2} \mathrm{O}_{2}$ at room temperature for $10 \mathrm{~min}$ to eliminate the activity of endogenous peroxidase. Tissue sections were subsequently incubated with anti-periostin monoclonal antibody (1:65; cat. no. GTX100602; Bioworld Technology, Inc., St. Louis Park, MN, USA) at $5^{\circ} \mathrm{C}$ overnight and biotin-conjugated rabbit anti-rat $\operatorname{IgG}(1: 300$; cat. no. SP-9001; Hebei Bio-High Technology, Hebei, China) at $5^{\circ} \mathrm{C}$ for $1 \mathrm{~h}$. Finally, sections were incubated with HRP-conjugated streptavidin at room temperature for $10 \mathrm{~min}$ and were visualized using 3,3'-diaminobenzidine tetrahydrochloride (Bio-High technology, Hebei, China). Yellow granules observed in tissue cells using a light microscope at x400 and extracellular matrix were considered to indicate a positive result.

Reverse transcription-quantitative polymerase chain reaction (RT-qPCR) and western blotting. The right lung lobes were frozen in liquid nitrogen immediately following harvesting, and were subsequently used for RT-qPCR and western blotting. Total RNA was isolated using an Ultrapure RNA kit (CWbio Co., Ltd., Beijing, China) according to the manufacturer's protocol. Reverse transcription was performed using a HiFi-MMLV cDNA kit (CWbio Co., Ltd.) according to manufacture's protocol. Following this, qPCR of genes were performed on an ABI7500 system (Applied Biosystems; Thermo Fisher Scientific, Inc.) using SYBR ${ }^{\mathrm{TM}}$ Green PCR Master Mix (Thermo Fisher Scientific, Inc.) with the following thermocycling conditions, $50^{\circ} \mathrm{C}$ for $3 \mathrm{~min}, 95^{\circ} \mathrm{C}$ for $3 \mathrm{~min}$, and 40 cycles of $95^{\circ} \mathrm{C}$ for $10 \mathrm{sec}$ and $60^{\circ} \mathrm{C}$ for $30 \mathrm{sec}$. Primers for periostin and GAPDH (used as control) were designed based on the mRNA sequence. Primer sequences were as follows: Periostin, forward 5'-ACTCCGTGTCTTCGTGTATC-3' and reverse 5'-CTTTCTTCATTAGTCATTCCCT-3'; and GAPDH, forward 5'-TGGAGTCTACTGGCGTCTT-3' and reverse 5'-TGTCATATTTCTCGTGGTTCA-3'. Relative gene expression levels were quantified using the $2^{-\Delta \Delta \mathrm{Cq}}$ method (21).

Expression of periostin and TGF- $\beta 1$ protein was determined by western blotting in lung tissue samples. Firstly, lung issue samples were homogenized using the mortar in the liquid nitrogen and lysed using RIPA lysis buffer contained with phosphatase inhibitor cocktail at $4^{\circ} \mathrm{C}$ for $30 \mathrm{~min}$. Following this, the lysates were centrifuged at $10,000 \mathrm{x} \mathrm{g}, 4^{\circ} \mathrm{C}$ for $10 \mathrm{~min}$ and supernatants were harvested, quantified using the BCA Protein assay kit, and boiled with loading buffer [10\% (v/v) $\mathrm{SDS}, 50 \%$ (v/v) glycerol, $0.2 \mathrm{M} 8$ tris- $\mathrm{HCl}(\mathrm{pH} 6.8), 0.1 \mathrm{M}$ dithiothreitol and bromophenol blue]. Following this, $15 \mu \mathrm{g}$ protein for each sample was loaded into each lane of a $4 \%$ 


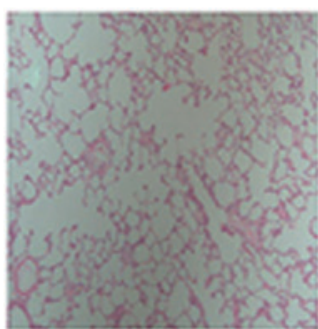

C group
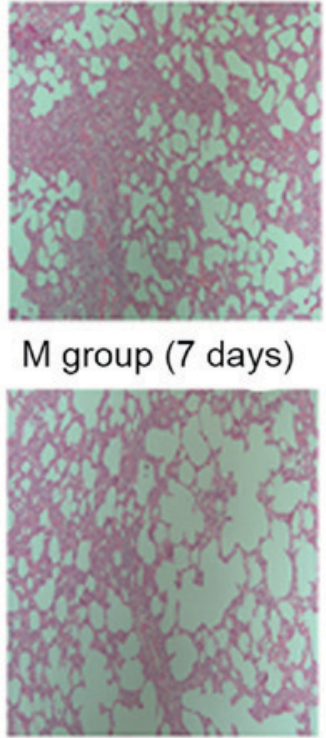

$\mathrm{P}$ group (7 days)
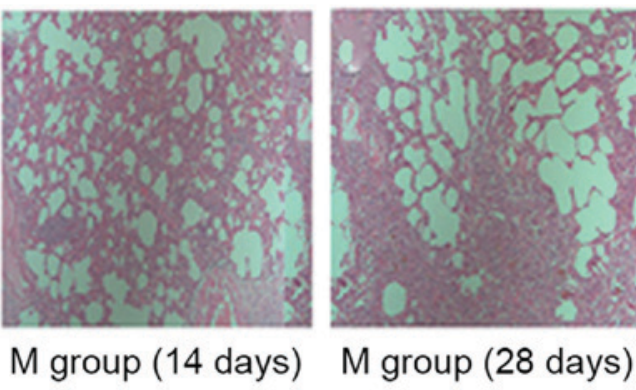

M group (28 days)
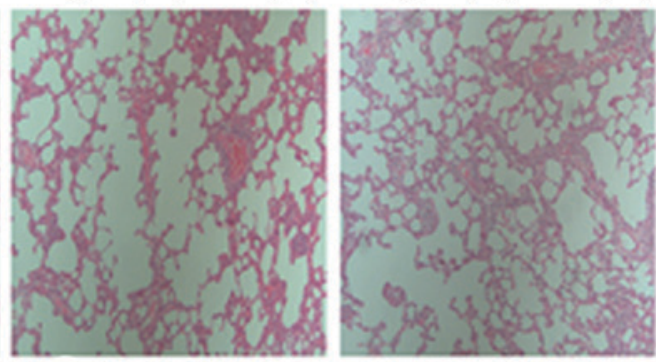

P group (28 days)

Figure 1. Histological examination of the antifibrotic effect of pirfenidone using hematoxylin-eosin staining at x200 magnification. C group, control group; M group, model group; P group, pirfenidone group.

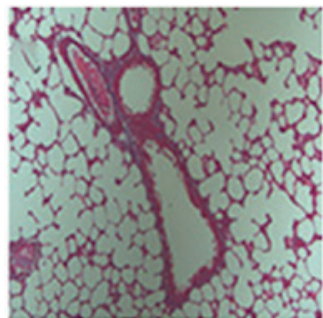

C group
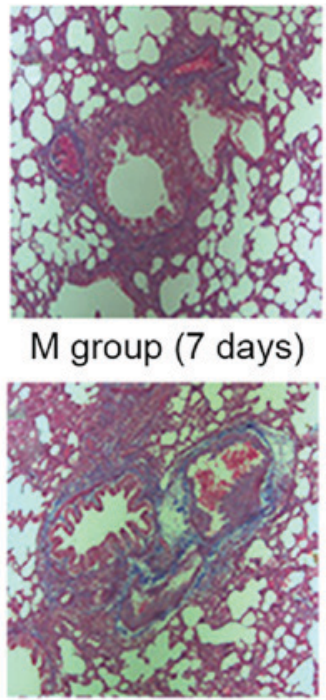

P group (7 days)
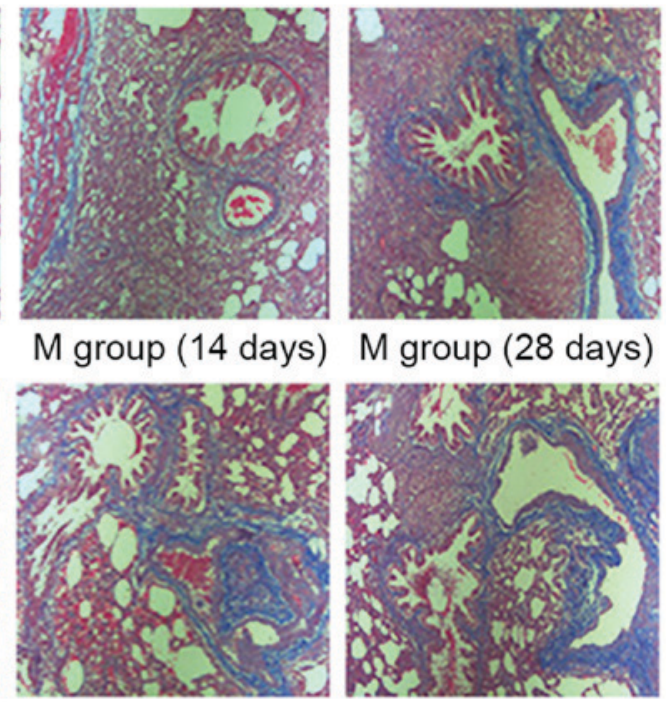

P group (14 days)

$P$ group (28 days)

Figure 2. Histological examination of the antifibrotic effect of pirfenidone using Masson's trichrome staining at x200 magnification. C group, control group; M group, model group; P group, pirfenidone group.

SDS-PAGE and separated by $12 \%$ SDS-PAGE. Then, proteins were electro-transferred to a polyvinylidene difluoride membrane. The membranes were blocked with $5 \%$ non-fat milk at room temperature for $1 \mathrm{~h}$. Membranes were subsequently incubated with primary antibodies against TGF- $\beta 1(1: 1,000$; cat. no. BZ00924) and periostin (1:1,000; cat. no. BZ1801) purchased from Bioworld Technology, Inc. (St. Louis Park, $\mathrm{MN}, \mathrm{USA})$ at $4^{\circ} \mathrm{C}$ overnight, and $\beta$-actin monoclonal antibody (1:1,000; cat. no. TA811000; OriGene Technologies, Inc., Beijing, China) as an internal control. $\beta$-actin was incubated with the membranes at $4^{\circ} \mathrm{C}$ overnight. The following day, samples were incubated with HRP-conjugated secondary antibody (1:3,000; cat. no. TA140003; OriGene Technologies, Inc.) at room temperature for $1 \mathrm{~h}$. Enhanced chemiluminescent autoradiography reagent was then used to visualize the specific protein bands. Total TGF- $\beta 1$, periostin and $\beta$-actin levels were determined using inbuilt software in the EC3-600 BioImaging System (UVP, LLC, Phoenix, AZ, USA).

Statistical analysis. SPSS v19.0 (IBM Corp., Armonk, NY, USA) was used for statistical analysis. Data are presented as the mean \pm standard deviation. Significant differences among groups were identified via one-way analysis of variance and Tukey's tests for multiple comparisons. Correlations between 

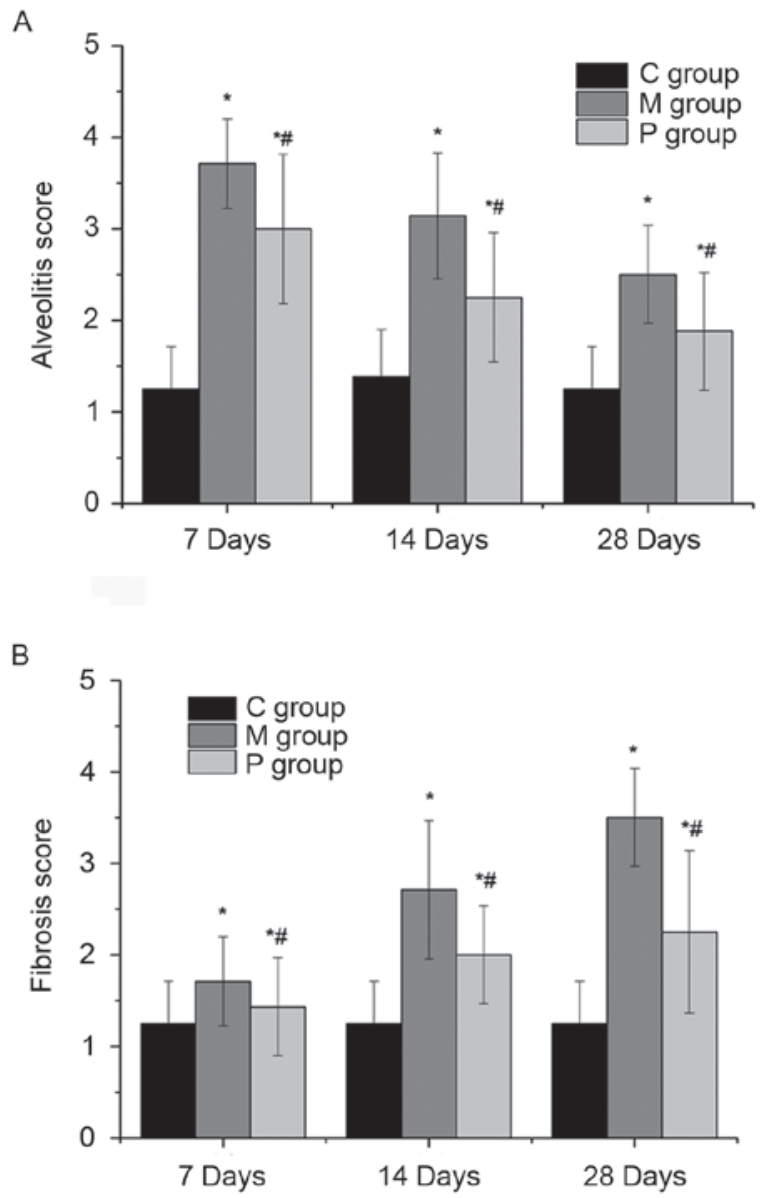

Figure 3. Semi-quantitative histology using scoring system to assess (A) alveolitis and (B) fibrosis in hematoxylin and eosin- and Masson's trichrome-stained sections. ${ }^{*} \mathrm{P}<0.05$ vs. $\mathrm{C}$ group; ${ }^{\text {}} \mathrm{P}<0.05$ vs. $\mathrm{M}$ group. $\mathrm{C}$ group, control group; $\mathrm{M}$ group, model group; $\mathrm{P}$ group, pirfenidone group.

the expression of periostin and TGF- $\beta 1$, fibrosis score, and the content of hydroxyproline were analyzed using Spearman's rank correlation coefficient test. $\mathrm{P}<0.05$ was considered to indicate a statistically significant difference.

\section{Results}

Pirfenidone ameliorates bleomycin-induced pulmonary fibrogenesis. The effects of pirfenidone on bleomycin-induced fibrogenesis were evaluated by $\mathrm{H} \& \mathrm{E}$ and Masson's staining and the pathology was quantified using a scoring system for alveolitis and fibrosis. As presented in Figs. 1-3, a lung phenotype of thickening of the alveolar interval, distortion of lung structure and fibrosis induced by bleomycin was observed compared with the control. Pirfenidone treatment was able to alleviate the bleomycin-induced fibrotic effects on rat lungs. Following statistical analysis, alveolitis and fibrosis scores were demonstrated to be significantly decreased following pirfenidone treatment throughout the experiment course (7, 14 and 28 days) when compared with that of the M group $(\mathrm{P}<0.05)$.

Pirfenidone decreases hydroxyproline content in bleomycin-challenged rats. The effect of pirfenidone on lung hydroxyproline content at days 7,14 , and 28 is presented in

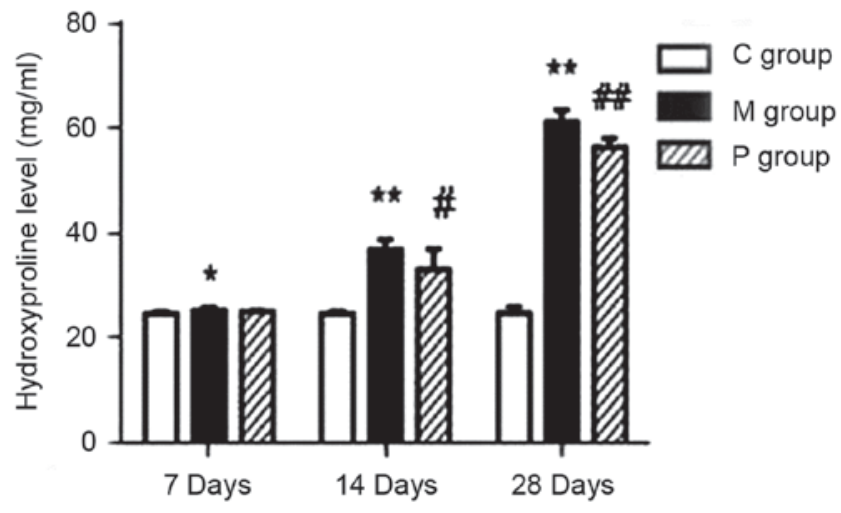

Figure 4. Quantitative examination of hydroxyproline levels in lung tissue. ${ }^{*} \mathrm{P}<0.05,{ }^{* *} \mathrm{P}<0.01$ vs. $\mathrm{C}$ group; ${ }^{\#} \mathrm{P}<0.05,{ }^{\# \#} \mathrm{P}<0.01$ vs. $\mathrm{M}$ group. $\mathrm{C}$ group, control group; $\mathrm{M}$ group, model group; $\mathrm{P}$ group, pirfenidone group.

Fig. 4. There was a significant increase of hydroxyproline content in the $\mathrm{M}$ group compared with the $\mathrm{C}$ group at days 7 , 14 and 28 , respectively $(\mathrm{P}<0.05$ or $\mathrm{P}<0.01)$. However, pirfenidone administration significantly ameliorated this increase at days $14(\mathrm{P}<0.05)$ and $28(\mathrm{P}<0.01)$.

Pirfenidone decreases the expression of periostin and TGF- $\beta 1$ in bleomycin-challenged rats. Representative histological features at day 14 as well as the expression of periostin during the whole course in different groups are presented in Fig. 5A-D. Periostin immunohistochemistry of the $\mathrm{C}$ group demonstrated weak peribronchial deposition, and periostin was rarely observed in pulmonary epithelial cells and alveolar macrophages, whereas in the $\mathbf{M}$ group, a strong expression of periostin was observed in the interstitia, particularly in the fibrotic foci, and periostin was also evident in the thickened alveolar walls underneath regenerating epithelial cells. In the $\mathrm{P}$ group, however, the expression of periostin was markedly decreased in the interstitial (Fig. 5A).

The periostin expression was detected at both the mRNA and protein level. RT-qPCR results demonstrated that periostin mRNA was significantly higher in the $\mathrm{M}$ group than in the $\mathrm{C}$ group at each time point $(\mathrm{P}<0.05$ or $\mathrm{P}<0.01$; Fig. $5 \mathrm{~B})$, whereas pirfenidone significantly inhibited the transcription of periostin when compared with the $\mathrm{M}$ group at days $7(\mathrm{P}<0.05)$ and 14 ( $\mathrm{P}<0.01$; Fig. 5B). Similar results of periostin expression at the protein level were achieved via western blotting, although there was no significant difference between the $\mathrm{M}$ and $\mathrm{P}$ groups at day 7 (Fig. 5C and D).

The expression of TGF- $\beta 1$ in different groups was also measured by western blotting and the results are presented in Fig. 5E and F. The expression of TGF- $\beta 1$ was significantly increased in the $\mathrm{M}$ group than that in the $\mathrm{C}$ group at days 7 $(\mathrm{P}<0.05), 14(\mathrm{P}<0.01)$, and 28 (data not shown), which was significantly ameliorated at days $14(\mathrm{P}<0.01)$ and 28 (data not shown).

Periostin expression is significantly correlated with hydroxyproline and TGF- $\beta 1$ content. As demonstrated in Fig. 6A and B, periostin expression was positively correlated with the hydroxyproline $(\mathrm{r}=0.9186, \mathrm{P}<0.001)$ and TGF- $\beta 1(\mathrm{r}=0.8748$, $\mathrm{P}<0.001)$ content. In addition, Fig. $6 \mathrm{C}$ also demonstrated that 
A

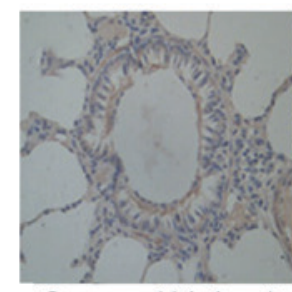

C group (14 days)

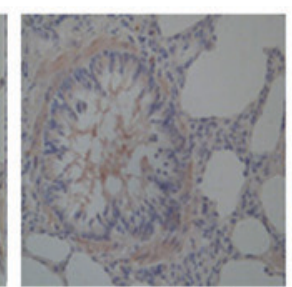

M group (14 days)

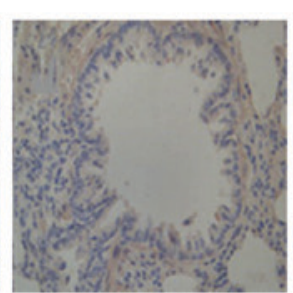

P group (14 days)
B

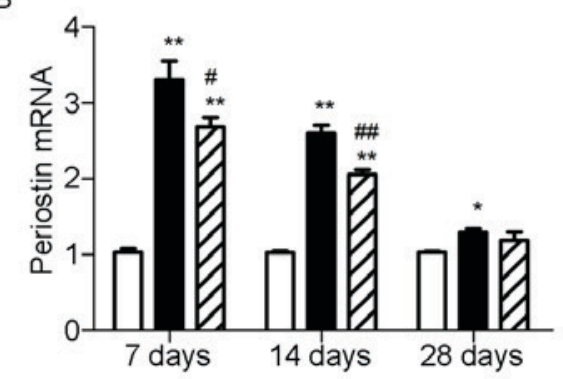

C

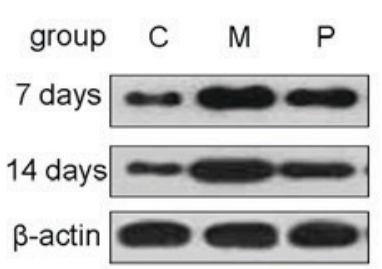

$$
\text { D }
$$

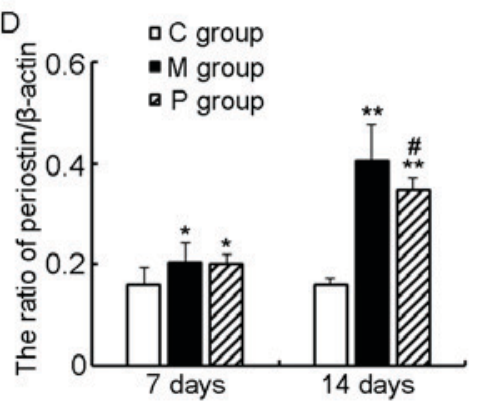

$E$

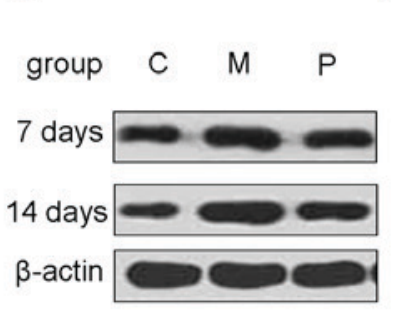

$\mathrm{F}$

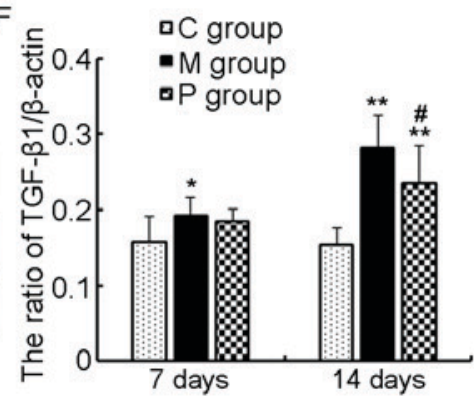

Figure 5. Identification of periostin expression in lung tissue. (A) Immunohistochemistry for periostin performed at day 14 at $x 400$ magnification. (B) Quantitative examination of periostin mRNA in lung tissue. (C) Identification and (D) quantification of periostin expression using western blotting. (E) Identification and (F) quantification of TGF- $\beta 1$ expression using western blot. ${ }^{*} \mathrm{P}<0.05,{ }^{* *} \mathrm{P}<0.01$ vs. $\mathrm{C}$ group; ${ }^{*} \mathrm{P}<0.05,{ }^{\# \#} \mathrm{P}<0.01$ vs. M group. TGF, transforming growth factor; $\mathrm{C}$ group, control group; $\mathrm{M}$ group, model group; $\mathrm{P}$ group, pirfenidone group.
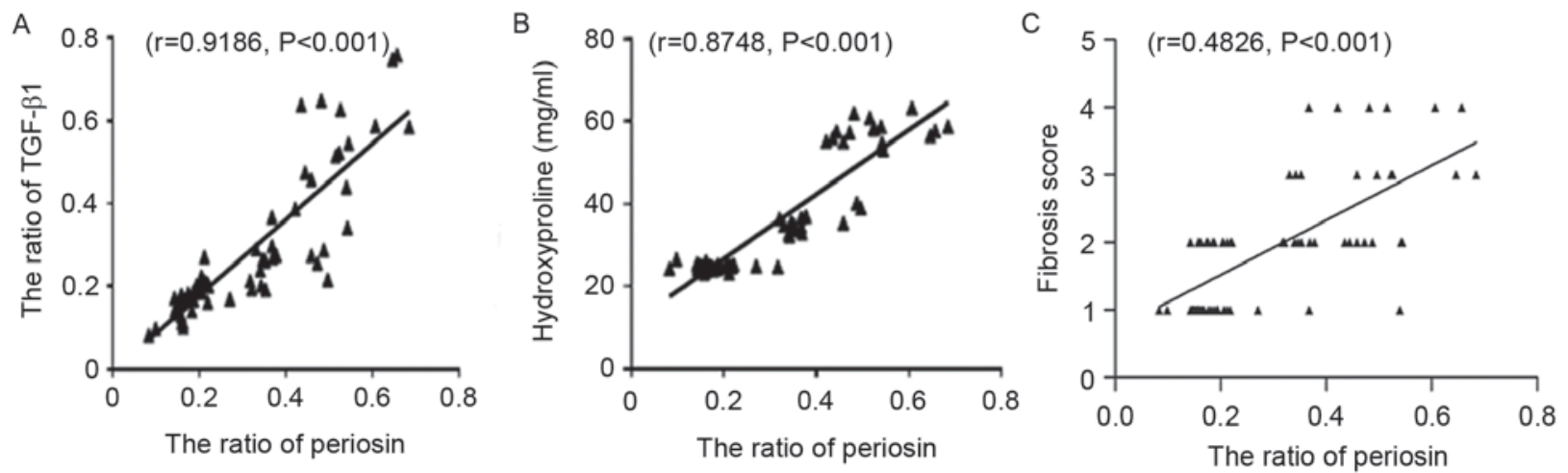

Figure 6. Correlation analysis of periostin protein with (A) TGF- $\beta 1$, (B) hydroxyproline and (C) fibrosis score in lung tissue. TGF, transforming growth factor.

periostin expression was positively correlated with the fibrosis score $(\mathrm{r}=0.4826, \mathrm{P}<0.001)$.

\section{Discussion}

The bleomycin-induced lung fibrosis rat model is typically used to evaluate the underlying mechanisms of lung fibrosis and to identify potential therapeutic interventions. In the present study, through the use of a bleomycin-treated rat model, it was demonstrated that pirfenidone administration reduced the extent of inflammation and fibrosis, and that pirfenidone attenuated the expression of periostin and TGF- $\beta 1$ mRNA and protein in pulmonary fibrosis.

Pirfenidone is the first antifibrotic drug to be approved for the treatment of IPF. It has been demonstrated that pirfenidone is therapeutically effective for the fibrosis of several other organs, such as the heart, liver and kidney (22). The effective anti-fibrotic effect of pirfenidone is attributed to suppressing the expression of various pulmonary cytokines including TGF- $\beta 1$ (23), platelet-derived growth factor (24), tumor necrosis factor- $\alpha$ (25) and lung basic-fibroblast growth factor (15), and factors associated with oxidative stress such as NADPH oxidase (NOX)4 and NOX1 (26). Furthermore, a previous study has demonstrated that pirfenidone was able to reduce the formation of NOD-like receptor pyrin domain containing 3 inflammasome, and subsequently down-regulate the expression of interleukin-1 $\beta$ (27). Furthermore, Oku et al (15) previously investigated the antifibrotic activity of pirfenidone compared with a reference agent prednisolone in a bleomycin-induced lung fibrosis murine model; a decrease in pulmonary fibrosis, reduced lesions and reduced hydroxyproline level were observed following 30 or $100 \mathrm{mg} / \mathrm{kg}$ pirfenidone administration were observed. In accordance with these findings, administration with $50 \mathrm{mg} / \mathrm{kg}$ pirfenidone was demonstrated to reduce the extent of inflammation and fibrosis induced by bleomycin in the present study. 
TGF- $\beta 1$ serves a vital role in promoting fibrosis progression, as it is able to activate various chemokines and cytokines to induce extracellular matrix protein synthesis and suppress collagen degradation, leading to a transition from fibroblasts to myofibroblasts $(28,29)$. TGF- $\beta 1$ has been demonstrated to induce periostin expression and serves an essential role in periostin promoting fibrosis (13). Sidhu et al (11) previously demonstrated that periostin upregulated TGF- $\beta$ production, which is integral to periostin-induced collagen deposition and epithelial-mesenchymal transition. Furthermore, treatment with TGF- $\beta 1$ increased periostin mRNA levels via modulating the focal adhesion kinase pathway in murine periodontal ligament fibroblasts (30). The present study indicated that TGF- $\beta 1$ and periostin were significantly suppressed by pirfenidone administration. Furthermore, expression of periostin and TGF- $\beta 1$ exhibited the same trend in different groups. These findings suggest that TGF- $\beta 1$ and periostin act as a positive feedback loop in the progression of fibrosis.

Periostin, which is a newly identified matrix protein, has been reported to be associated with the process of various fibrotic disorders, such as cardiac, liver and kidney fibrosis. Periostin serves its role in pulmonary fibrosis in the inflammatory and fibroproliferative phases. In recent years, its role in lung fibrosis has been investigated. Previous studies have identified that periostin was significantly elevated in plasma and lung tissue of patients with IPF $(12,13)$, and high peristin may indicate clinical progression of IPF (13). It has been demonstrated that elevated expression of periostin has positive effects on keloid fibroblasts proliferation, collagen synthesis, migration and invasion under hypoxic conditions (31). It has been suggested that periostin promotes fibrosis following bleomycin treatment via modulating chemokine production and recruiting inflammatory cells (6), and through promoting extracellular matrix deposition, mesenchymal cell proliferation and wound closure (13). In the present study, it was identified that periostin protein and mRNA was significantly increased following bleomycin treatment. These results suggested the important role of periostin and its potential as a target for the treatment of pulmonary fibrosis. The preliminary investigation on the underlying mechanism of pirfenidone on bleomycin-induced fibrosis in the present study may provide a theoretical basis for further exploration on the effects of pirfenidone inhibiting fibrosis.

In conclusion, the present findings suggest that the antifibrotic effect of pirfenidone may be achieved by suppression of periostin and TGF- $\beta 1$ expression in rat pulmonary fibrogenesis. Decreasing periostin expression may be another antifibrotic mechanism for pirfenidone through down-regulating TGF- $\beta 1$. However, the current study has a limitation in elucidating how periostin signals cross-talk with TGF- $\beta$ signals. Therefore, further study is required to determine the exact mechanism of action of pirfenidone on periostin expression.

\section{Acknowledgements}

The authors wish to thank Dr. Ji Weina (The Affiliated Hospital of Qingdao University, Qingdao, China) for assistance with the present experiments and Dr. Ren Dunqiang (The Affiliated Hospital of Qingdao University) for valuable discussion.

\section{Funding}

No funding was received.

\section{Availability of data and materials}

The datasets used and/or analyzed during the current study are available from the corresponding author on reasonable request.

\section{Authors' contributions}

WY designed the current study. FG and XS performed the analysis and data interpretation. WY drafted the manuscript. XS revised the manuscript for important intellectual content. All authors read and approved the final manuscript.

\section{Ethics approval and consent to participate}

The present study was performed in accordance with the guidelines of the National Institutes of Health (NIH) Guide for the Care and Use of Laboratory Animals, and was approved by the Animal Care and Use Committee of the Medical College of Qingdao University (Qingdao, China).

\section{Consent for publication}

Not applicable.

\section{Competing interests}

The authors declare that they have no competing interests.

\section{References}

1. Raghu G, Collard HR, Egan JJ, Martinez FJ, Behr J, Brown KK, Colby TV, Cordier JF, Flaherty KR, Lasky JA, et al: An official ATS/ERS/JRS/ALAT statement: Idiopathic pulmonary fibrosis: Evidence-based guidelines for diagnosis and management. Am J Respir Crit Care Med 183: 788-824, 2011

2. Demedts M, Behr J, Buhl R, Costabel U, Dekhuijzen R, Jansen HM, MacNee W, Thomeer M, Wallaert B, Laurent F, et al: High-dose acetylcysteine in idiopathic pulmonary fibrosis. N Engl J Med 353: 2229-2242, 2005.

3. Norris RA, Moreno-Rodriguez R, Hoffman S and Markwald RR: The many facets of the matricelluar protein periostin during cardiac development, remodeling, and pathophysiology. J Cell Commun Signal 3: 275-286, 2009.

4. Hamilton DW: Functional role of periostin in development and wound repair: Implications for connective tissue disease. J Cell Commun Signal 2: 9-17, 2008.

5. Ontsuka K, Kotobuki Y, Shiraishi H, Serada S, Ohta S, Tanemura A, Yang L, Fujimoto M, Arima K, Suzuki S, et al: Periostin, a matricellular protein, accelerates cutaneous wound repair by activating dermal fibroblasts. Exp Dermatol 21: 331-336, 2012.

6. Uchida M, Shiraishi H, Ohta S, Arima K, Taniguchi K, Suzuki S, Okamoto M, Ahlfeld SK, Ohshima K, Kato S, et al: Periostin, a matricellular protein, plays a role in the induction of chemokines in pulmonary fibrosis. Am J Respir Cell Mol Biol 46: 677-686, 2012.

7. Ruan K, Bao S and Ouyang G: The multifaceted role of periostin in tumorigenesis. Cell Mol Life Sci 66: 2219-2230, 2009.

8. Jackson-Boeters L, Wen W and Hamilton DW: Periostin localizes to cells in normal skin, but is associated with the extracellular matrix during wound repair. J Cell Commun Signal 3: 125-133, 2009.

9. Oka T, Xu J, Kaiser RA, Melendez J, Hambleton M, Sargent MA, Lorts A, Brunskill EW, Dorn GW II, Conway SJ, et al: Genetic manipulation of periostin expression reveals a role in cardiac hypertrophy and ventricular remodeling. Circ Res 101: 313-321, 2007. 
10. Takayama G, Arima K, Kanaji T, Toda S, Tanaka H, Shoji S, McKenzie AN, Nagai H, Hotokebuchi $T$ and Izuhara $K$ : Periostin: A novel component of subepithelial fibrosis of bronchial asthma downstream of IL-4 and IL-13 signals. J Allergy Clin Immunol 118: 98-104, 2006.

11. Sidhu SS, Yuan S, Innes AL, Kerr S, Woodruff PG, Hou L, Muller SJ and Fahy JV: Roles of epithelial cell-derived periostin in TGF-beta activation, collagen production, and collagen gel elasticity in asthma. Proc Natl Acad Sci USA 107: 14170-14175, 2010.

12. Okamoto M, Hoshino T, Kitasato Y, Sakazaki Y, Kawayama T, Fujimoto K, Ohshima K, Shiraishi H, Uchida M, Ono J, et al: Periostin, a matrix protein, is a novel biomarker for idiopathic interstitial pneumonias. Eur Respir J 37: 1119-1127, 2011.

13. Naik PK, Bozyk PD, Bentley JK, Popova AP, Birch CM, Wilke CA, Fry CD, White ES, Sisson TH, Tayob N, et al: Periostin promotes fibrosis and predicts progression in patients with idiopathic pulmonary fibrosis. Am J Physiol Lung Cell Mol Physiol 303: L1046-L1056, 2012.

14. Cicko S, Grimm M, Ayata K, Beckert J, Meyer A, Hossfold M, Zissel G, Idzko M and Müller T: Uridine supplementation exerts anti-inflammatory and anti-fibrotic effects in an animal model of pulmonary fibrosis. Respir Res 16: 105-115, 2015.

15. Oku H, Shimizu T, Kawabata T, Nagira M, Hikita I, Ueyama A, Matsushima S, Torii M and Arimura A: Antifibrotic action of pirfenidone and prednisolone: Different effects on pulmonary cytokines and growth factors in bleomycin-induced murine pulmonary fibrosis. Eur J Pharmacol 590: 400-408, 2008.

16. Azuma A, Nukiwa T, Tsuboi E, Suga M, Abe S, Nakata K, Taguchi Y, Nagai S, Itoh H, Ohi M, et al: Double-blind, placebo-controlled trial of pirfenidone in patients with idiopathic pulmonary fibrosis. Am J Respir Crit Care Med 171: 1040-1047, 2005.

17. Taniguchi H, Ebina M, Kondoh Y, Ogura T, Azuma A, Suga M, Taguchi Y, Takahashi H, Nakata K, Nakata K, et al: Pirfenidone in idiopathic pulmonary fibrosis. Eur Respir J 35: 821-829, 2010.

18. Moeller A, Ask K, Warburton D, Gauldie J and Kolb M: The bleomycin animal model: A useful tool to investigate treatment options for idiopathic pulmonary fibrosis? Int J Biochem Cell Biol 40: 362-382, 2008

19. Szapiel SV, Elson NA, Fulmer JD, Hunninghake GW and Crystal RG: Bleomycin-induced interstitial pulmonary disease in the nude, athymic mouse. Am Rev Respir Dis 120: 893-899, 1979.

20. Fulmer JD, Bienkowski RS, Cowan MJ, Breul SD, Bradley KM, Ferrans VJ, Roberts WC and Crystal RG: Collagen concentration and rates of synthesis in idiopathic pulmonary fibrosis. Am Rev Respir Dis 122: 289-301, 1980
21. Livak KJ and Schmittgen TD: Analysis of relative gene expression data using real-time quantitative PCR and the 2(-delta delta C(T)) method. Methods 25: 402-408, 2001.

22. Macías-Barragán J, Sandoval-Rodríguez A, Navarro-Partida J and Armendáriz-Borunda J: The multifaceted role of pirfenidone and its novel targets. Fibrogenesis Tissue Repair 3: 16, 2010.

23. Iyer S, Gurujeyalakshmi G and Giri S: Effects of pirfenidone on transforming growth factor-beta gene expression at the transcriptional level in bleomycin hamster model of lung fibrosis. J Pharmacol Exp Ther 291: 367-373, 1999.

24. Gurujeyalakshmi G, Hollinger M and Giri S: Pirfenidone inhibits PDGF isoforms in bleomycin hamster model of lung fibrosis at the translational level. Am J Physiol 276: L311-L318, 1999.

25. Nakazato H, Oku H, Yamane S, Tsuruta Y and Suzuki R: A novel anti-fibrotic agent pirfenidone suppresses tumor necrosis factor-alpha at the translational level. Eur J Pharmacol 446: 177-185, 2002.

26. Gaggini F, Laleu B, Orchard M, Fioraso-Cartier L, Cagnon L, Houngninou-Molango S, Gradia A, Duboux G, Merlot C, Heitz F, et al: Design, synthesis and biological activity of original pyrazolo-pyrido-diazepine,-pyrazine and-oxazine dione derivatives as novel dual Nox4/Nox1 inhibitors. Bioorg Med Chem 19: 6989-6999, 2011.

27. Wang Y, Wu Y, Chen J, Zhao S and Li H: Pirfenidone attenuates cardiac fibrosis in a mouse model of TAC-induced left ventricular remodeling by suppressing NLRP3 inflammasome formation. Cardiology 126: 1-11, 2013.

28. Fernandez IE and Eickelberg O: The impact of TGF- $\beta$ on lung fibrosis: From targeting to biomarkers. Proc Am Thorac Soc 9: 111-116, 2012.

29. Thannickal VJ, Lee DY, White ES, Cui Z, Larios JM, Chacon R, Horowitz JC, Day RM and Thomas PE: Myofibroblast differentiation by transforming growth factor-betal is dependent on cell adhesion and integrin signaling via focal adhesion kinase. J Biol Chem 278: 12384-12389, 2003.

30. Wen W, Chau E, Jackson-Boeters L, Elliott C, Daley T and Hamilton D: TGF- $\beta 1$ and FAK regulate periostin expression in PDL fibroblasts. J Dental Res 89: 1439-1443, 2010.

31. Zhang Z, Nie F, Kang C, Chen B, Qin Z, Ma J, Ma Y and Zhao X: Increased periostin expression affects the proliferation, collagen synthesis, migration and invasion of keloid fibroblasts under hypoxic conditions. Int J Mol Med 34: 253-261, 2014.

This work is licensed under a Creative Commons Attribution-NonCommercial-NoDerivatives 4.0 International (CC BY-NC-ND 4.0) License. 